\title{
Damage to the reversion - Some misconceptions
}

Received (in revised form): 23rd May, 2004

\section{Peter Beckett FRICS}

is a chartered surveyor, and Senior Partner of Beckett \& Kay, a firm specialising in landlord and tenant work, with particular emphasis on damage to the reversion, leasehold enfranchisement, value investment, and recovery. He was the landlord's valuer in the leading case on dilapidations, Shortlands Investments Ltd $v$ Cargill plc [1995]. He is a member of the RICS Dilapidations Working Group, and a joint author of the RICS Guidance Note on Dilapidations (4th edition).

\begin{abstract}
S18(1) of the Landlord and Tenant Act 1927 is the best-known example of the idea of damage to the reversion. It expresses an attractive proposition - that a landlord cannot recover more than he has lost. That proposition applies in broad terms to all claims in dilapidations. The author explores 13 misconceptions about how this principle affects a landlord's claim once a (normally, commercial) lease has expired. The linkage of the valuation process to the schedule of dilapidations is considered, as is the analytical nature of the exercise required. He says that margin of error has no place in a calculation of damage to the reversion, and that justification is required if the damage to the reversion appears to be less than the cost of works. Four important cases are mentioned: Shortlands $v$ Cargill; Mason $v$ TotalFinaElf; Rainbow Estates $v$ Tokenhold; and Jervis $v$ Harris.
\end{abstract}

\section{Keywords:}

claim, dilapidations, landlord, loss, tenant, valuation

Peter Beckett

Beckett \& Kay LLP

87 Regent Street

London $\mathrm{W}_{1} \mathrm{~B} 4 \mathrm{EH}, \mathrm{UK}$

Tel: +44 (o) 2074396667

Fax: +44 (o) 2074396668

E-mail:

peterbeckett@beckettandkay.co.uk

\section{INTRODUCTION}

Damage to the reversion is a loss of value in a landlord's property as a result of a tenant's failure to comply with covenants. This concept causes a lot of muddled thinking. Most of the trouble arises because the state of repair of a property represents a small proportion of its value, at least in high-value locations. In central London, for example, the site may well represent two-thirds of the value of a property. The state of the building therefore may have rather a small effect on value. Furthermore, the margin of error in the valuation of a property is several percentage points - some say $10-15$ per cent either way. This often leads even experienced property people to suppose that the state of a building, being often well within that margin of error, has no real effect on value, causing them to think that there can be no damage to the reversion.

One example of the idea of damage to the reversion is found in s. 18(1) of the Landlord and Tenant Act 1927, relating to repair: 


\begin{abstract}
'Limb 1'
'Damages for breach of a covenant. .. to keep or put premises in repair during the currency of a lease or to leave or put premises in repair at the termination of a lease. . shall in no case exceed the amount (if any) by which the value of the reversion (whether immediate or not) in the premises is diminished owing to the breach of such covenant...'.

'Limb 2'

'... and in particular no damages shall be recovered for a breach of any such covenant... to leave or put premises in repair at the termination of a lease, if it is shown that the premises, in whatever state of repair they might be would at or shortly after the termination of the tenancy have been or be pulled down or such structural alterations made therein as would render valueless the repairs covered by the covenant.'
\end{abstract}

All that s. 18(1) does is express an attractive proposition - that a landlord cannot recover more than he has lost. It deals only with repair but, not surprisingly, the principle applies to all breaches of covenant.

Notice that the phrase 'damage to the reversion' is not used in the statute at all. The expression drawn from the statute should really be 'diminution in the value of the landlord's reversion'. Nonetheless, because it is the usual phrase, this paper subsequently uses 'damage to the reversion'.

Damage to the reversion is a subtle thing, to be thought out carefully on every occasion, and benefiting from careful analysis. It does not, as a general statement, negate the tenant's contractual obligation to repair, nor does it generally eliminate the effect of repair on value.

In looking at misconceptions about damage to the reversion, we start with the most naïve (of which the reader is never guilty, I am sure), passing to the most sophisticated. It is a purely personal view, but I believe an overriding misconception is that judges look favourably on tenants who ask, in effect, to be relieved of their covenants. On the whole, judges are a bit unsympathetic to parties who come to the court to be relieved of contractual obligations freely and solemnly entered into. Of course, the judiciary will apply the law with complete objectivity, but it is inevitable that somebody who wants to be relieved of a contractual obligation is at a disadvantage in a finely balanced case.

\title{
MISCONCEPTION 1: OUTGOING TENANTS ARE RARELY LIABLE FOR DISREPAIR
}

Obviously, in the case of 'Limb 2' where the building is going to be demolished, or drastically altered throughout, tenants are normally relieved of their covenants on expiry. 'Limb 2' is explicit on that point. Landlords can hardly claim for a tenant's failure to repair (or to comply with any covenant) if the subject building is to be demolished. In the more common case, however, where no demolition or structural alteration is intended, full relief from the covenants of the lease is rare. In everything that follows in this paper, 'Limb 1' is being considered rather than 'Limb 2'.

When considering a typical building, it is unlikely that the walls of the building will cease to be of use. If they are in a poor state of repair, they will have to be repaired. The cost will be the measure of the damage to the reversion, as far as those walls go, and the landlord will be compensated 


\section{There is usually a liability}

The schedule plays a part for it (assuming the tenant's repairing covenants covered the walls, of course). Usually the roof, gutters and downpipes will survive any change in the building. If they are in a poor state of repair, they will have to be repaired or replaced. It is also a relatively rare case for all the windows and doors in the external envelope of the building to be replaced if they are in good repair. External redecoration may have to be carried out. So, even if the landlord wants to make quite significant changes inside the building, works will have to be done outside if the outgoing tenant has not already done them. The measure of damage to the landlord's reversion is the cost of rectifying any such breaches of covenant.

Even inside (other than in well-located shops), it is actually quite a rare case for damage to the reversion to be zero. (In the case of well-located shops, ingoing tenants often utterly refit and refurbish the interior of the shop even if it is in good repair, because they want to stamp their own retail character on it.) In most other cases, much of the interior survives and must be placed in a good state of repair, if the landlord is not to lose by it.

In short, regarding both the exterior and the interior of the building, if the building is in disrepair, it is likely that the landlord will suffer a loss. If there is such a loss, the cost of repair (plus consequential losses) is the damage to the reversion, and the landlord can sue for it.

One way to look at this as a valuer surveyor is to stand in the street and look at the building. If it really seems that no repairs are required even outside, or that any repairs required are of literally no value to the landlord, then there is some prospect of zero damage to the reversion. If there are any doubts, or if any failure of the tenant's covenants has any effect on value, then one has a dilapidations case on one's hands.

\section{MISCONCEPTION 2: THE VALUER DOES NOT NEED THE SCHEDULES TO DO THE VALUATION}

To understand why this is a misconception, it needs to be remembered that, to assess damage to the reversion, two valuations are needed. The property is being valued as it actually was at the date of expiry. That figure is then compared with the value the property would have had, if the tenant had complied with his covenants. It is immediately apparent that the schedules of dilapidations are part of the valuation, and a first stab at damage to the reversion. This is not just my view; for example, to quote from the Shortlands case: 'In most cases the cost of repairs is a good guide to the difference in value of the reversion'.

Of course, if one was able to produce comparables that demonstrated it, one would be entitled to say that, in this case, the market is not logical and that the repairs do not figure. Any such evidence would have to be very compelling, and one probably would have to provide some explanation to the court (if matters went so far) as to how such an illogical situation arose.

It should be remembered that this is not a property due for demolition, so it is likely that some of the wants of repair, to put it no higher, will have to be rectified by an actual or hypothetical purchaser. The landlord can claim damages for that rectification. There may be areas of the building where it can be said that no damage has occurred for a specific reason, such as supersession, which is discussed below. It is most unlikely that not 
a single breach of covenant inside or outside the building has any effect on the mind of a purchaser.

In the real world, it is most unlikely that any comparable evidence available will prove such an illogical proposition. One will have to go very close to the perfect standard of comparable evidence to prove the point. Two physically very similar properties will be needed, very close to one another and to the subject property, which were sold on the open market at more or less exactly the valuation date (which, by the way, is the date of expiry of the lease). One of these would have to be a property in a comparably poor state, and the other in a good state. Such perfect, open market evidence is most unlikely to be available, and therefore one will be thrown back on arguing the logic. If the argument is that disrepair makes no difference to the bid of a purchaser, and no specific reason can be given for that (such as one of the reasons discussed later), there may be difficulty convincing the court of the proposition.

\section{MISCONCEPTION 3: OUTGOING TENANTS DO NOT HAVE TO PAY MUCH FOR THEIR BREACHES}

The first port of call in considering the measure of damage to the reversion is the cost of works. Particularly where the landlord carries out those works and pays for them, it may be very difficult to say that he did not lose to that extent. In such a situation, it is hardly worth doing damage to the reversion valuation at all. All that such a valuation will reveal is that the property, worth $£ X$ in good order, is worth $£ X$ minus the cost of works (and consequential costs) in poor order.

In principle, this is so even if the landlord does not do the work. The first and most obvious estimate of the damage to the landlord's reversion is the cost of the works to which he is exposed by the tenant's failure to carry them out. The damage to the reversion valuation may only be a check that no special considerations have been left out of account. In the Shortlands case, what was effectively a residual valuation approach was approved by the court, and appended to the judgment. There were two valuations: one assuming compliance with covenants and, the other, the actual situation. The difference between the two valuations was little

Cost of works plays a part different from the cost of works (over and above the cost of works that the landlord would have been put to anyway), adjusted for consequential considerations.

To this extent, it seems that s. 18(1) has caused even experienced surveyors and valuers to 'take their eye off the ball'. In many simple situations, the difference (between the value the property would have had if the tenant had complied and the value it actually had) is the cost of works, plus consequential costs. Even in trickier situations, the cost of works is bound to figure in a valuation process designed to isolate the effect of the breaches alone. To quote from the judgment in the Mason case: ${ }^{2}$

\footnotetext{
'The diminution is to be assessed as at the lease expiry date. It involves two valuations of the landlord's interest. The first is on the assumption that the premises were then in the state that they would have been in if the tenant had performed his covenants. The second is of the premises in their actual state and condition at that
} 
Tenants should take the lead date... the purpose of the exercise is to isolate the effect on value of the tenant's failure to do the relevant works, from which it follows that the only variable between the two valuations is the works. All other factors are constants.'

\section{MISCONCEPTION 4: THE TENANT CAN LET THE LANDLORD MAKE THE RUNNING}

What appears to be rarely appreciated, by surveyors at least, is that in litigation to recover money for breaches of covenant the tenant is normally paying both sides' costs. Until the tenant makes a payment into court or a Part 36 Offer, he has not even begun to protect himself against costs. If the court finds that the tenant's liability is greater than zero, then the court will normally make the tenant pay the costs until the time when he makes a payment or an offer. (Under the Civil Procedure Rules (CPR), there may be some exceptions to this, but these again are beyond the scope of this paper.) As suggested above, the case where a damage to the reversion valuation will reduce the tenant's liability to zero is a rare case (except where the building is to be demolished), so the exposure to costs is very real.

Once a payment into court or Part 36 Offer is made, of course, a much more careful judgment has to be made on both sides. The landlord has to beat that payment or offer, otherwise he will be paying the tenant's costs from that date onwards. So for a tenant to 'let the landlord make the running' is dangerous, it is far better for the tenant to take some action. The best action any tenant can take is to do the work that appears to be needed before the end of the lease. There are two reasons for this:

- It places the landlord in the position of having to argue, not about whether work has or has not been done, but about the standard of the work. No judge is going to be thrilled by a landlord coming to him saying the work has not been done to an adequate standard. By contrast, if the work has not been done at all, then, on the face of it, that is a breach of covenant pure and simple, and the landlord will be more sympathetically received.

- The preparatory, administrative work can be done while the tenant is still in occupation. The tenant will face a claim for loss of rent, service charges, void rates etc if he leaves it to the landlord, for the following reasons.

- Before physical work can be done to a building, the party doing it needs to know exactly what is required. It is obvious that the landlord cannot know for sure until he recovers possession. He then instructs a surveyor, the surveyor inspects and prepares a specification, the specification is sent out to contractors, the contractors have to be given time to respond, the successful contractor will have to be chosen and then given time actually to appear on site. Until that moment, not a stroke of physical work is done to the building or the demise in question.

- Obviously, the tenant is in a position to carry out all those preparatory stages, which will last some weeks - perhaps even 
months - while he is still in occupation. If he does not do so, the landlord may be able to claim loss of rent and outgoings during the period in which the property is lying fallow.

Thus, leaving it to the landlord actually increases the costs, both in terms of standards and in terms of consequential losses. Moreover, the legal costs of a dilapidations case are formidable. This is because of the forensic nature of the examination of the schedule of dilapidations, item by item, and because of the complexity of any damage to the reversion valuation. It is not at all uncommon for the combined costs to exceed the amount of the claim. So 'who pays the costs of the litigation?' is a question that should loom very large in the minds of both parties. Where a tenant leaves the matter to the landlord, without making a payment into court or a Part 36 Offer, the tenant's costs will soon escalate out of hand. Consequently, the rule for a tenant is: do the work, or, if not, make a well-judged payment into court early on.

\section{MISCONCEPTION 5: IF THE PROPERTY CANNOT BE VALUED ACCURATELY, THERE IS NO LIABILITY}

There is a 'margin of error' around any valuation. Valuers recognise that it is not possible to put ' $a$ ' value on a property; there is always uncertainty as to what the value of the property would be at any given date. The margin of error varies, but it is usually something like 10-15 per cent either way. This means that a property valued at say $£ 1,000,000$ could sell for anything between $£ 850,000$ and $£ 1,150,000$, and that band could be wider.

This wide band of value has often confused those dealing with damage to the reversion. If property cannot be valued more accurately than this, they say, surely the effect of dilapidations is lost in that margin of error? This has been described as the 'practical man's approach', but it is actually just a misunderstanding. The two valuations - one assuming compliance with covenants and the other being the actual situation must be done on a consistent basis.

The job is to value the property as it actually was and to compare it with exactly the same property, as it would have been had the tenant complied with his covenants to repair. Obviously, whatever assumptions are made in

\section{Eliminate margin of error}

the 'compliance' valuation are also made in the 'actual' valuation. Margin of error has got nothing to do with it; in fact, one can demonstrate that to allow for a margin of error would result in an illogical and unacceptable result.

To illustrate, take two buildings in which there is $£ 20,000$ worth of repairs to be done. The first concerns a small building in the Midlands, say, worth $£ 60,000$ in good repair. The repairs therefore represent about one-third of the value of the property. Compare that with, say, a $£ 50 \mathrm{~m}$ office building in the City of London, where a single suite has been left in disrepair. In both cases, it is common sense that the loss to the landlord is $£ 20,000$ (taken together with consequential costs and, crucially, subject to the supersession factor-see below). If one took the view that margin of error was relevant, however, one would come to the conclusion that $£ 20,000$ was something the landlord could sue for in the first case, but not in the second - because it was too deeply buried in the margin of 
Even poor properties can be valued error - which cannot be right. The claim is about the same in both cases and the valuation must reflect that, which it will do as long as all other factors in the valuation are held constant, so as to isolate the effect of the disrepair. That is the job of the valuer - to isolate, and identify the effect of, the cost of works - not to bury it in the margin of error.

All one has to do is value the property exactly the same way in and out of compliance (see the quote from the Mason case above). Often, as discussed above, this will reveal that the difference is roughly the cost of works and consequential costs.

\section{MISCONCEPTION 6: IF THE PROPERTY IS DIFFICULT TO LET ANYWAY, THERE IS NO LIABILITY}

Limb 2 of s. 18(1) makes it clear that, if the subject matter of the covenants is to be destroyed, no damage can arise. One can envisage some cases where the property is not to be demolished but where, nonetheless, the breaches of covenant have no effect. Logically expressed, this is the case where the property has no value even if it is in compliance with the tenant's covenants. There probably are industrial buildings which are completely unlettable in any state, but where the market is such that one cannot justify demolishing them. Obviously, the 'damage to the reversion' valuation will show that the property is worthless whether or not it is in compliance with the tenant's covenants. In either state, it is worth zero, but this certainly would be a rare case.

Notice that it must be worth zero not a negative amount in both states see 'Misconception 10' below. Also, now that the mere ownership of land can give rise to expensive obligations, as with contamination, it is also important to ensure that no breach of covenant will create a liability, turning what would otherwise be a property of zero value into a property of negative value. Even in such an unusual case, the possibility of damage to the reversion is not ruled out. If the property has any kind of non-zero value, then breaches of covenant can damage it, and the valuer will have to identify the damage.

The reverse of this misconception is the idea that, if a landlord let the property well after expiry, there was no diminution. It could indicate that, of course, but usually a careful examination of the terms of the letting will show it did take the condition of the property into account somehow - perhaps via a rent-free period, a lower rent than would otherwise have been obtained, or a schedule of condition. The property belongs to the landlord. If he lets it for better than valuers expect, it is more likely that the valuers were wrong than that the condition of the property has been ignored.

\section{MISCONCEPTION 7: THE COST OF WORKS DOES NOT NEED TO BE ITEMISED WITH ANY CARE}

The terms 'supersession' and 'superseded' (sometimes spelled 'supercession' and 'superceded') are not used in the cases (as far as I am aware), or in s. 18(1), but they are helpful in thinking about damage to the reversion. The easiest way of explaining this concept is by way of example. Suppose that there are two rooms due to be amalgamated in the building. The lease has a provision that the whole of the demise, including its internal walls, 


\section{Supersession requires analysis}

must be fully repaired and decorated. Suppose the plaster is blown on the wall which is due to be demolished and that it needs decorating once that area has been re-plastered. What would be the purpose, from the landlord's point of view (let alone the tenant's), of doing that work? If the wall is to be demolished, what possible point would there be in replastering it and redecorating it before it is demolished? It would be a nonsensical and pointless thing to do, and the landlord cannot lose by it not being done. It is therefore said that the work of replastering and redecoration to that wall is superseded by the landlord's intention to demolish the wall. He has lost nothing by the tenant's breach of covenant and therefore he can recover nothing from him on that account.

It only requires brief acquaintance with this concept of 'supersession' to realise that the schedule of dilapidations actually has to be examined item by item to establish the extent of supersession. This will only not be necessary in a case where the landlord's intentions, short of demolition, are nonetheless so all-embracing that it is obvious that every repair will be superseded - a rare case, one would think and hard to imagine short of Limb 2.

\section{MISCONCEPTION 8: THE CAP ON THE CLAIM DOES NOT NEED TO BE EXPLAINED}

When the valuer presents his valuation to the court, he may have to explain why damage to the reversion differs from the cost of works. Indeed, in my opinion, it is probably necessary to go through the Scott Schedule (the document which sets out the parties' positions on the items in the schedule of dilapidations) and identify those items affected by supersession and those that are not. For example, in the case of the well-located shop mentioned above, all the items of internal repair might be bracketed and annotated 'superseded by the incoming tenant's shop fitting'. Again, it might be noted, against some works of repair to a bathroom soon to be changed to a kitchen, that the works will be 'superseded by conversion to a kitchen'. If an item cannot be said to be superseded in this way, it is not easy to see why it should not figure in the calculation the valuer is doing. After all, the valuer will have to allow for the cost of repairs in his valuation - for which a purchaser of the property will make an allowance - and this will affect value. An item of supersession will appear in the 'damage to the reversion' calculation because, by definition, it would not be included in the valuation of the property in a full state of repair.

In principle, every item either will be superseded or will be entered into the damage to the reversion calculation. The valuer therefore will need to show which is in which category. Obviously, the valuation will not end there, but the cost of works element in the valuation will. A proper justification of the use of the repair figures will require analysis.

\section{MISCONCEPTION 9: THERE IS ONLY A CAP ON REPAIR WORKS}

I once thought that, because s. 18(1) imposed a cap on claims for disrepair, claims for other breaches of covenant were not subject to a cap.

In other words, that claims for reinstatement, compliance with statutory obligations, decoration etc were not limited by damage to the reversion; but actually, they usually are. There are subtle differences between s. 18(1) 
S. $18(1)$ is only an example of a principle

Even negative values can be more negative

Even refurbishment may not eliminate a claim and the general common law method of assessing these losses, but these are beyond the scope of this paper, and possibly too subtle for surveyors to worry about anyway.

The principle in common law is that no one can claim in damages more than they have lost. In the 19th century, for reasons that are beyond me, the courts started to accept that repair was an exception to this rule. They decided that a landlord could claim for the breach of a covenant to repair, even if he had suffered nothing by it. It was this anomaly that s. 18(1) was intended to remedy. The anomaly having been remedied by statute, the general principle is this: whether the work is repairs covered by s. 18(1), or other breaches of covenant, the measure of the landlord's loss is normally the damage to his reversion.

\section{MISCONCEPTION 10: IF VALUE IS NEGATIVE, THERE CANNOT BE DAMAGE}

In the Shortlands case, which concerned a landlord with a leasehold interest in a bad market, the court refuted this misconception in the following way.

'If the premises had been delivered up in a state of good repair and decoration the premises would have had a negative value, but as they were delivered up in a bad condition, they had a worse negative value.

.

The diminution in value is the difference between the amount of money paid out by the willing transferor to the willing transferee:

- if the premises were delivered up in a condition in conformity with the covenants; and

- if the premises were delivered up in their actual condition.

There would be no willing "purchaser" if no money were paid to him.'

(Some liberties have been taken with the layout of this quotation for ease of exposition.)

\section{MISCONCEPTION 11: IF THERE IS DRASTIC REFURBISHMENT AFTER EXPIRY, THERE CANNOT BE DAMAGE}

This is now getting to the more subtle kind of misconception. Suppose one acts for a tenant and, a year after the tenant's lease is up and he has vacated, the landlord utterly refurbishes the building in a style and in a manner that would have neutralised any repairs the client might have carried out. Does that prove that there was no damage to the reversion in the areas of the building so affected? Well, it certainly would put the landlord on the back foot, because that is the kind of situation the 'damage to the reversion' principle is designed to avoid. It would also make it very difficult for the landlord to say that he never intended to do such a thing at the expiry date. There remains the possibility, however, that he could convince the court that, for reasons he would no doubt have to state, he had entirely different 
Replacement may be repair

There may be claims during the term intentions at the date of expiry. Sometimes he may be genuinely overtaken by events. War breaks out in some of the reported cases, for example. The market might suddenly undergo an abrupt change. It may not be conclusive even if he demolished the building some time after the lease expired, if it was genuinely not his intention to do so at the date of expiry of the tenancy.

Knowing exactly how a landlord would have to go about convincing a court of his genuine intention is too difficult a legal question to be tackled here. The valuer must be alert to this possibility though, that the tenant still will be liable because of the landlord's state of mind at the expiry date, even if claimed repair work was utterly superseded at a later date. It has been established that the valuation has to be done at the expiry date, hence the importance of the landlord's state of mind at that date.

\section{MISCONCEPTION 12: NO DAMAGE ARISES IF AN ITEM IS REPLACED}

Suppose a window is damaged, it is obvious that the measure of damage to the reversion is normally the cost of repairing the window. In a normal case, s. 18(1) has no impact on this at all. Suppose, however, that the landlord intends, regardless of the state of repair of that window, to replace it, perhaps to introduce double-glazing. In such a case, s. 18(1) removes the obligation from the tenant altogether. Even if the tenant had repaired the window to a perfect standard and handed it over in that condition to the landlord, the repair of the window would have been superseded by the landlord's intention to replace the window. He would have suffered no loss had the tenant failed to repair the window and s. 18(1) therefore says that he can have no compensation for any such failure.

Suppose now that the window is in an appalling state of repair and, say, it is a single-glazed window. Suppose, furthermore, that physical repair would be uneconomic and the landlord has to replace it. In doing so, he chooses to replace it with a double-glazed window. He can recover the cost of replacing the window, although obviously he can only recover the cost that would have been incurred by replacing it with a single-glazed window to a similar specification to the old window. For the landlord to succeed in recovering this cost, of course, he has to establish that, but for the disrepair, he would not have replaced the window.

\section{MISCONCEPTION 13: THERE IS NO DAMAGE WHERE TENANTS ARE CONTINUING}

Actually, I would hesitate to call this a misconception, because in most likely circumstances it is true. A tenant continuing to pay rent, suffer rent reviews and enjoy lease renewals upon the basis that the building is in good repair (even if it is not), and who carries the repairing obligation forward is hardly causing any damage to the landlord's reversion. Occasionally there might be a case where the tenant's financial substance might be thought to be insufficient to carry out a repair in the future, but is sufficient to carry it out now, or where the disrepair is damaging rental value elsewhere on the landlord's holding. But these are subtleties beyond the scope of this paper. 
Until a few years ago, one could have expressed more confidence in the proposition that continuing tenants are rarely at risk from claims for dilapidations, but this view has been weakened by two relatively recent cases, themselves also beyond the scope of this paper:

— Orders for specific performance are possible $;^{3}$

- In a suitable case, a landlord can enter the premises and carry out the works himself. He can probably recover the cost if the lease says that to do so is recovery of a debt, but probably not where it says recovery is by way of an action for damages.

(C) Peter Beckett 2005

\section{Notes}

(1) Shortlands Investments Ltd $v$ Cargill plc [1995] 08 EG 163.

(2) Mason $v$ TotalFinaElf UK Ltd [2003] All ER (D) 191.

(3) Rainbow Estates Ltd $v$ Tokenhold Ltd [1998].

(4) Jervis $v$ Harris [1996]. 